\title{
Inactivation of Anthracyclines by Serum Heme Proteins
}

\author{
Brett A. Wagner, ${ }^{\dagger} \S$ Lynn M. Teesch, ${ }^{\ddagger}$ Garry R. Buettner, ${ }^{\dagger}$, Bradley E. Britigan, ${ }^{\#, \|}$ \\ C. Patrick Burns, ${ }^{\dagger}$ and Krzysztof J. Reszka*,\#,II \\ Department of Internal Medicine, Molecular Analysis Facility, Department of Radiation Oncology, Free Radical \\ and Radiation Biology Graduate Program, University of Iowa, Roy J. and Lucille A. Carver College of \\ Medicine, The University of Iowa Holden Comprehensive Cancer Center, Iowa City, Iowa, 52242, The Veterans \\ Affairs Medical Center, Cincinnati, Ohio 45220, and Department of Internal Medicine, University of Cincinnati,
} Cincinnati, Ohio 45267

\section{Received January 2, 2007}

\begin{abstract}
We have previously shown that the anticancer agent doxorubicin undergoes oxidation and inactivation when exposed to myeloperoxidase-containing human leukemia HL-60 cells, or to isolated myeloperoxidase, in the presence of hydrogen peroxide and nitrite. In the current study we report that commercial fetal bovine serum (FBS) alone oxidizes doxorubicin in the presence of hydrogen peroxide and that nitrite accelerates this oxidation. The efficacy of inactivation was dependent on the concentration of serum present; no reaction was observed when hydrogen peroxide or serum was omitted. Peroxidase activity assays, based on oxidation of 3,3',5,5'-tetramethylbenzidine, confirmed the presence of a peroxidase in the sera from several suppliers. The peroxidative activity was contained in the $>10000 \mathrm{MW}$ fraction. We also found that hemoglobin, a heme protein likely to be present in commercial FBS, is capable of oxidizing doxorubicin in the presence of hydrogen peroxide and that nitrite further stimulates the reaction. In contrast to intact doxorubicin, the serum + hydrogen peroxide + nitrite treated drug appeared to be nontoxic for PC3 human prostate cancer cells. Together, this study shows that (pseudo)peroxidases present in sera catalyze oxidation of doxorubicin by hydrogen peroxide and that this diminishes the tumoricidal activity of the anthracycline, at least in in vitro settings. Finally, this study also points out that addition of $\mathrm{H}_{2} \mathrm{O}_{2}$ to media containing FBS will stimulate peroxidase-type of reactions, which may affect cytotoxic properties of studied compounds.
\end{abstract}

\section{Introduction}

Peroxidases are heme proteins that utilize $\mathrm{H}_{2} \mathrm{O}_{2}$ to convert substrates to reactive metabolites. We have previously reported that human promyelocytic leukemia HL-60 cells, which are rich in MPO, ${ }^{1}$ as well as isolated MPO and LPO enzymes, catalyze oxidation of anthracycline anticancer drugs in the presence of $\mathrm{H}_{2} \mathrm{O}_{2}$. A facilitating cofactor in this reaction is $\mathrm{NO}_{2}^{-}(1,2)$; acetaminophen and salicylic acid also enhance the reaction (3, 4). This peroxidase-dependent metabolism causes inactivation of the anthracyclines as evidenced by their suppressed in vitro toxicity in human leukemia HL-60 cells, human prostate cancer PC3 cells, and rat cardiac H9c2 myocytes $(2,5)$. This inactivation is due to the oxidation-initiated degradation of anthracyclines to 3-methoxyphthalic acid (3MePA) and 3-methoxysalicylic acid (3MeSA) (Figure 1), which appear to be considerably less cytotoxic than the parent anthracycline $(2,5)$. The peroxide required for these oxidations was provided exogenously, but it is known that cancer cells themselves produce $\mathrm{H}_{2} \mathrm{O}_{2}(6,7)$. In

* Address correspondence to Krzysztof J. Reszka, Ph.D., Department of Internal Medicine, University of Cincinnati Medical Center, 231 Albert Sabin Way, P.O. Box 670557, Cincinnati, OH 45267. Phone: (513) 5586608. Fax: (513) 558-0852. E-mail: reszkakj@ucmail.uc.edu.

Department of Internal Medicine, University of Iowa.

Molecular Analysis Facility, University of Iowa.

$\S$ Department of Radiation Oncology, University of Iowa.

\# The Veterans Affairs Medical Center.

"University of Cincinnati.

1 Abbreviations: ABAH, 4-aminobenzoic acid hydrazide; DOX, doxorubicin (Adriamycin); FBS, fetal bovine serum; Hb, hemoglobin; LPO, lactoperoxidase; MPO, myeloperoxidase; 3MePA, 3-methoxyphthalic acid; 3MeSA, 3-methoxysalicylic acid; TMB, 3,3',5,5'-tetramethylbenzidine.

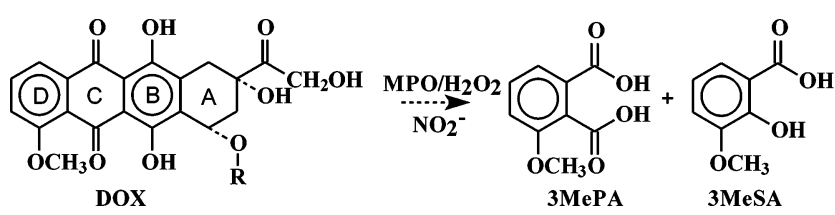

Figure 1. Oxidation of DOX by $\mathrm{MPO} / \mathrm{H}_{2} \mathrm{O}_{2}$ in the presence of nitrite leads to its degradation to 3-methoxyphthalic acid (3MePA) and 3-methoxysalicylic acid (3MeSA). $\mathrm{R}=$ daunosamine.

addition, we have previously reported that cancer cells exposed to anthracyclines increase their intracellular hydrogen peroxide concentration (8).

It is known that serum contains peroxidase activity $(9,10)$ and that the concentration of the serum peroxidase in patients with inflammatory vascular disease increases some 10-fold to nanomolar levels (11). Therefore, we wished to determine whether (pseudo)peroxidases present in the 5-10\% fetal bovine serum (FBS), used routinely in many cell culture studies, can inactivate anthracyclines similar to other peroxidase systems. If so, it might complicate conclusions regarding their cytotoxicity in vitro and in vivo and may have an impact on cancer biology and biochemical pharmacology of anthracycline agents. Therefore, we studied the capacity of FBS to inactivate DOX, as a representative anthracycline, and the conditions under which this inactivation may occur.

\section{Experimental Procedures}

Materials. DOX, $\mathrm{NaNO}_{2}(99+\%), \mathrm{H}_{2} \mathrm{O}_{2}(8.8 \mathrm{M}), 3,3^{\prime}, 5,5^{\prime}-$ tetramethylbenzidine (TMB), dimethyl formamide, 3MeSA, catalase, equine hemoglobin (ferric form, metHb), methimazole, 
aminobenzoic acid hydrazide (ABAH), and azide were obtained from Sigma Chemical Company (St. Louis, MO). 3MePA was synthesized as described (2). All other chemicals were of the highest purity available. Fetal bovine sera were obtained from diverse commercial suppliers. According to manufacturers' specifications, all FBS contain trace amounts of hemoglobin $(<25 \mathrm{mg} \%)$.

Cell Culture. Human prostate cancer cell line PC3 was obtained from the American Type Culture Collection (Manassas, VA) and maintained in minimum essential media supplemented with $10 \%$ FBS, L-glutamine $(1.5 \mathrm{mM})$, streptomycin $(76 \mu \mathrm{g} / \mathrm{mL})$ (Gibco Invitrogen, Grand Island, NY), and penicillin $(76 \mathrm{U} / \mathrm{mL})$ in a humidified atmosphere containing $5 \% \mathrm{CO}_{2}$ at $37{ }^{\circ} \mathrm{C}$. Cells were passed by detaching with trypsin/EDTA, and those used in the experiments had been passed less than 20 times.

Oxidation of DOX by $\mathbf{F B S} / \mathrm{H}_{2} \mathrm{O}_{2}$. Oxidation of DOX was measured following changes in the drug's characteristic absorption band at $480 \mathrm{~nm}$ using an Agilent diode array spectrophotometer model 8453 (Agilent Technologies, Inc., Chesterfield, MO). To DOX in RPMI 1640 media, or in phosphate buffer saline (pH 7.0), containing FBS at indicated concentrations, was added $1 \mathrm{mM} \mathrm{H}_{2} \mathrm{O}_{2}$ (freshly diluted from a $8.8 \mathrm{M}$ stock) and/or $1 \mathrm{mM} \mathrm{NaNO} 2(10 \mu \mathrm{L} /$ $\mathrm{mL}$ from a $100 \mathrm{mM} \mathrm{NaNO}{ }_{2}$ stock solution). Experiments were carried out at $37{ }^{\circ} \mathrm{C}$ in a tissue culture incubator with a $5 \% \mathrm{CO}_{2}$ humidified atmosphere or at room temperature $\left(22^{\circ} \mathrm{C}\right)$ for some experiments. At specific time points, aliquots of the samples were withdrawn and centrifuged at $16000 \mathrm{~g}$ for $2 \mathrm{~min}$. The supernatants were then read at $480 \mathrm{~nm}$. The amount of drug remaining in the supernatants was calculated using $\epsilon_{480}=11500 \mathrm{M}^{-1} \mathrm{~cm}^{-1}$ for anthracyclines (12). The dependence of DOX oxidation on $\left[\mathrm{H}_{2} \mathrm{O}_{2}\right]$ was determined by measuring the initial rate of the loss of absorbance at $480 \mathrm{~nm}$ over the period up to $30 \mathrm{~min}$ after start of the reaction $\left(\mathrm{H}_{2} \mathrm{O}_{2}\right.$ addition $)$ in $100 \%$ FBS and at $\left[\mathrm{H}_{2} \mathrm{O}_{2}\right]$ ranging from 0 to $0.5 \mathrm{mM}$. For some experiments FBS was dialyzed against water for 3 days through Spectrapor 6000-8000 MW cutoff dialysis membrane (Spectrum Medical Ind. Inc., Rancho Dominguez, CA).

Oxidation of DOX by metHb/ $\mathbf{H}_{2} \mathrm{O}_{2}$. To DOX $(10 \mu \mathrm{M})$ in phosphate buffer $\mathrm{pH} 7.0(50 \mathrm{mM})$ was added metHb $(1.3 \mu \mathrm{M}$ in heme) and $A_{480}$ was measured every minute for $5 \mathrm{~min}$, after which $5 \mu \mathrm{L}$ of $\mathrm{H}_{2} \mathrm{O}_{2}$ stock solution was added to a final concentration of $0.37 \mathrm{mM}$ and measurements were continued for $20 \mathrm{~min}$. Similar experiments were performed in the presence of $\mathrm{NaNO}_{2}(0.30 \mathrm{mM})$. FerrylHb was prepared by adding $\mathrm{H}_{2} \mathrm{O}_{2}(0.37 \mathrm{mM})$ to metHb $(50$ $\mu \mathrm{M})$. Decrease in absorbance at 500 and $630 \mathrm{~nm}$, characteristic of metHb, was concomitant with the formation of a new band at 545 $\mathrm{nm}$, which is interpreted as a redox transition from metHb to ferrylHb (13). An aliquot of DOX solution was then added to this preformed ferrylHb and absorption spectra were measured in $1 \mathrm{~min}$ intervals. Samples were measured in a spectrophotometric cuvette (1 cm light path) at ambient temperature during continuous stirring with a microstirrer. The initial concentration of metHb solutions was determined by measuring its absorbance at 405 and $500 \mathrm{~nm}$ $\left(\epsilon_{405}=179 \mathrm{mM}^{-1} \mathrm{~cm}^{-1}\right.$ and $\left.\epsilon_{500}=10 \mathrm{mM}^{-1} \mathrm{~cm}^{-1}\right)$ (14).

Peroxidase Activity Assays. The peroxidase activity of FBS samples was assessed using the TMB oxidation assay as described in (15). Different volumes of media or sera were placed in $50 \mathrm{mM}$ sodium acetate buffer ( $\mathrm{pH}$ 5.4) to a total sample volume of 3.05 $\mathrm{mL}$. Then $50 \mu \mathrm{L}$ of a solution containing $100 \mathrm{mM}$ TMB in dimethyl formamide was added to the samples and mixed. The assay was initiated by mixing $200 \mu \mathrm{L}$ of $5.25 \mathrm{mM}$ hydrogen peroxide in sodium acetate buffer to the samples. The samples were then incubated at room temperature for $3 \mathrm{~min}$, after which the reaction was quenched with the addition of $100 \mu \mathrm{L}(0.3 \mathrm{mg} / \mathrm{mL})$ of catalase and $3.4 \mathrm{~mL}$ of ice-cold $200 \mathrm{mM}$ acetic acid in water. Immediately, the samples were mixed and then centrifuged at $1500 \mathrm{~g}$ for $5 \mathrm{~min}$. The supernatants' absorptions were then read at $655 \mathrm{~nm}$. Sensitivity was sufficient to detect peroxidase activity with as little as $0.3 \%$ by volume FBS.

Peroxidase Activity in Fractioned Sera. Tissue culture grade FBS was placed into Amicon YM-10 10000 molecular weight cutoff centrifugal filter devices (Millipore Corporation, Bedford, MA) and according to manufacture's instructions they were centrifuged at $1800 \mathrm{~g}$ for $3 \mathrm{~h}\left(5^{\circ} \mathrm{C}\right)$. Pooled fractions were then analyzed for the ability to oxidize doxorubicin and TMB as compared to unfractionated sera.

Determination of Serum Heme Content. The heme concentration in FBS was determined using the method described in (16). First the heme was extracted from FBS samples into chloroform by vigorous shaking and then centrifuged to separate the organic phase. The absorbance of the chloroform extract was measured at specific wavelengths $(388,450$, and $330 \mathrm{~nm})$ and the absorption parameter $A_{\mathrm{c}}$ was calculated using the formula $A_{\mathrm{c}}=2 A_{388}-A_{450}$ $-A_{330}$. The actual concentration of the heme in FBS samples was determined using this $A_{\mathrm{c}}$ value and a calibration curve prepared using known concentrations of hemin. Samples from five different suppliers were analyzed in triplicate.

Mass Spectrometry. Doxorubicin and the drug's oxidation products were analyzed by HPLC combined with mass spectrometry and tandem mass spectrometry as described earlier (2).

Clonogenic Survival. PC3 cells previously seeded at 500-1000 cells/plate were incubated in the presence of intact or oxidized doxorubicin at $37{ }^{\circ} \mathrm{C}$ in a humidified incubator with $5 \% \mathrm{CO}_{2}$ for 10 days. After this, the cells were fixed, stained, and counted to determine their clonogenic survival (18).

\section{Results}

Oxidation of DOX by Serum. When DOX was incubated in FBS in the presence of $\mathrm{H}_{2} \mathrm{O}_{2}$, the drug's characteristic absorption band at $480 \mathrm{~nm}$ decreased, indicating its oxidation. The extent of DOX oxidation depended on time of incubation and serum and $\mathrm{H}_{2} \mathrm{O}_{2}$ concentrations. First we studied oxidation of DOX by measuring changes in absorbance at $480 \mathrm{~nm}$ as a function of time. When DOX was incubated with $10 \% \mathrm{FBS}$ in RPMI 1640 in the presence of $1 \mathrm{mM} \mathrm{H}_{2} \mathrm{O}_{2}$ and $1 \mathrm{mM} \mathrm{NaNO}_{2}$, its concentration decreased by about $52 \%$ during a $60 \mathrm{~min}$ incubation (Figure 2A, trace d). The loss of the drug was slower when $\mathrm{NaNO}_{2}$ was omitted (Figure 2A, trace c) and no loss was observed in the presence of $\mathrm{NaNO}_{2}$ but without $\mathrm{H}_{2} \mathrm{O}_{2}$ (Figure $2 \mathrm{~A}$, trace b).

To examine the dependence of the efficacy of DOX oxidation on [FBS], the drug was incubated in PBS (50 mM, pH 7.0) containing $\mathrm{H}_{2} \mathrm{O}_{2}(1 \mathrm{mM})$ and $\mathrm{NaNO}_{2}(1 \mathrm{mM})$ in the presence of increasing proportions of FBS. Figure 2B shows changes in DOX concentrations following $1 \mathrm{~h}$ incubation. When both $\mathrm{H}_{2} \mathrm{O}_{2}$ and $\mathrm{NaNO}_{2}$ were present, the largest loss of DOX, $\Delta[\mathrm{DOX}] \sim$ $20 \mu \mathrm{M}$ or $\sim 89 \%$ decrease, was observed when about $15 \%$ serum had been added, and no further decrease in the drug concentration occurred at higher FBS content (Figure 2B, trace d). When $\mathrm{NaNO}_{2}$ was omitted, the oxidation occurred at a slower rate and did not level off until about $40 \%$ serum was present (Figure $2 \mathrm{~B}$, trace $\mathrm{c}$ ). There was no apparent oxidation of DOX in the absence of $\mathrm{H}_{2} \mathrm{O}_{2}$ whether $\mathrm{NaNO}_{2}$ was present or not, even at the highest FBS content used (Figure 2B, traces a and b).

The rate of DOX oxidation was dependent on $\left[\mathrm{H}_{2} \mathrm{O}_{2}\right]$. In the $\left[\mathrm{H}_{2} \mathrm{O}_{2}\right]$ range of $25-500 \mu \mathrm{M}$, the initial rate of DOX oxidation increased linearly with $\left[\mathrm{H}_{2} \mathrm{O}_{2}\right]$ (Figure 3 ).

Peroxidase Activity in Serum. The above observations are similar to those made using isolated LPO and MPO enzymes $(1,2)$ and suggest the presence of a peroxidase in FBS preparations. The peroxidase activity of FBS was determined by measuring oxidation of TMB. Figure 4A shows that there is a linear relationship between the amount of FBS present in the sample and the amount of TMB oxidized. Typical peroxidase inhibitors methimazole, $\mathrm{ABAH}$, and azide markedly quenched TMB oxidation, with $\mathrm{ABAH}$ being the most effective (Figure $4 \mathrm{~A}$, inset). Using the TMB assay, we determined peroxidase 

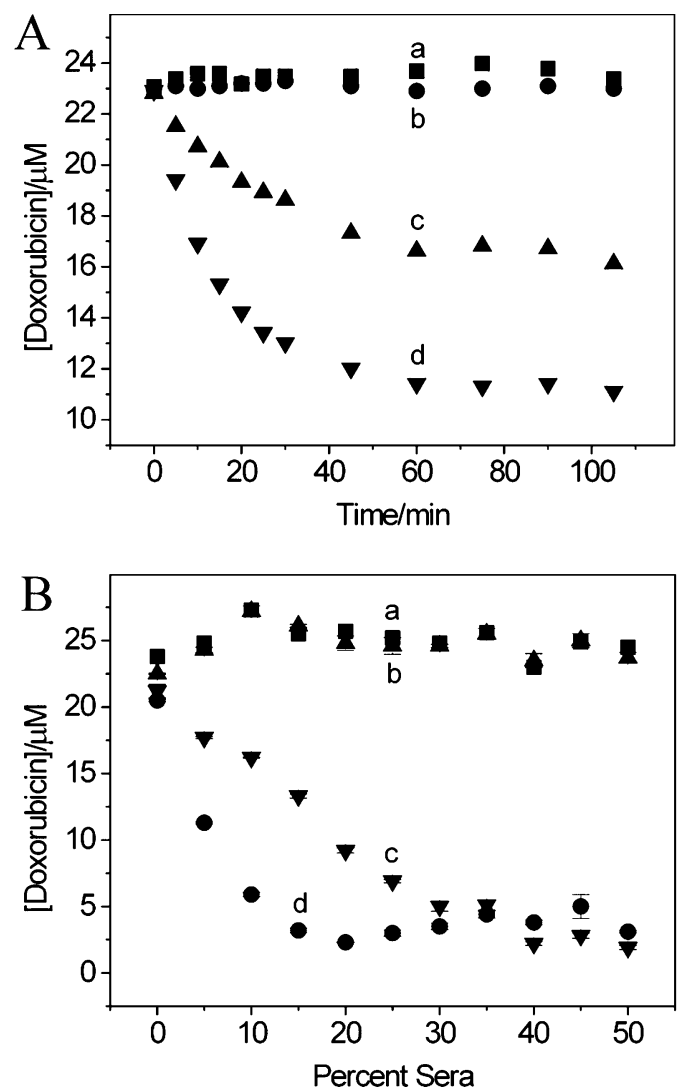

Figure 2. FBS and $\mathrm{H}_{2} \mathrm{O}_{2}$ oxidize DOX as monitored spectrophotometrically at $480 \mathrm{~nm}$. (A) Time course of oxidation of DOX $(23 \mu \mathrm{M})$ in RPMI 1640 containing 10\% FBS: (a) drug alone; (b) same as (a) + $1 \mathrm{mM}$ nitrite; (c) same as (a) $+1 \mathrm{mM} \mathrm{H}_{2} \mathrm{O}_{2}$; (d) same as (a) $+1 \mathrm{mM}$ nitrite $+1 \mathrm{mM} \mathrm{H}_{2} \mathrm{O}_{2}$. (B) Effect of FBS concentration on DOX oxidation. FBS was placed at various amounts in sodium phosphate buffer $(50 \mathrm{mM}, \mathrm{pH} 7.0)$ and incubated for $1 \mathrm{~h}$ at $37^{\circ} \mathrm{C}$ with DOX $(\sim 23 \mu \mathrm{M})$ and cosubstrates: (a) drug alone; (b) same as (a) $+1 \mathrm{mM}$ nitrite; (c) same as (a) $+1 \mathrm{mM} \mathrm{H}_{2} \mathrm{O}_{2}$; (d) same as (c) $+1 \mathrm{mM}$ nitrite.

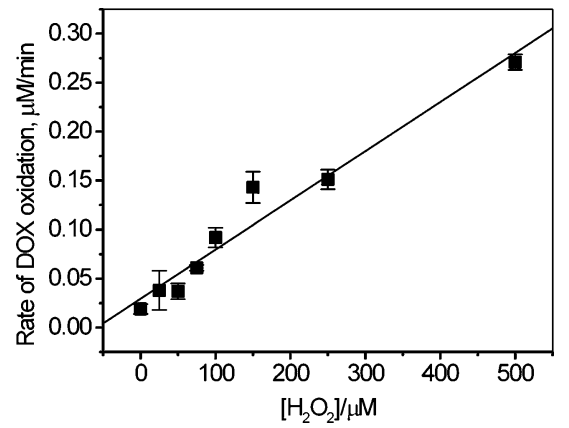

Figure 3. Rate of oxidation of DOX in FBS is dependent on the concentration of $\mathrm{H}_{2} \mathrm{O}_{2}$. The reaction was carried out in 100\% FBS and was monitored by measuring absorbance at $480 \mathrm{~nm}$. The initial DOX concentration was $15 \mu \mathrm{M}$. Data are the means $\pm \mathrm{SE}$ of three replicates.

activity in FBS from different manufacturers. Figure 4B demonstrates that there is appreciable activity in all samples studied.

Fractionation Studies. We have previously found that LPO and MPO systems oxidize anthracyclines only in the presence of a catalytic cofactor, a good peroxidase substrate, such as nitrite, acetaminophen, or salicylic acid (1-3). In contrast, hemin and a low molecular weight heme peptide, microperoxidase 11 , catalyzed oxidation of anthracyclines by $\mathrm{H}_{2} \mathrm{O}_{2}$ without any cofactors $(5,18)$. Also, myoglobin, a protein with pseudoperoxidase activity, supports oxidation of DOX by $\mathrm{H}_{2} \mathrm{O}_{2}$ alone (5, 19). In an attempt to characterize the peroxidase found in sera,
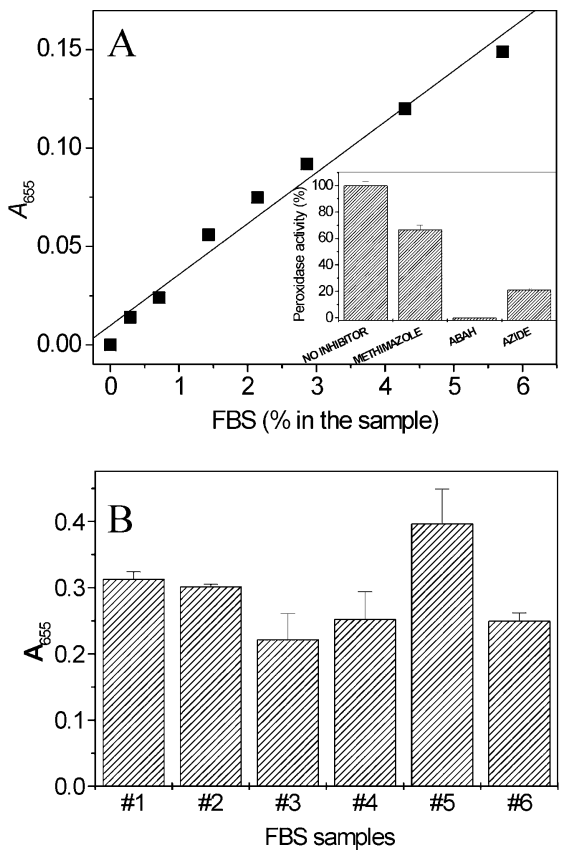

Figure 4. FBS has peroxidase activity. (A) Peroxidase activity as measured by the oxidation of tetramethylbenzidine (TMB). Increasing volumes of FBS (Gibco) were placed into the peroxidase assay in $\mathrm{pH}$ 5.4 buffer $\left(50 \mathrm{mM}\right.$, sodium acetate) containing $\mathrm{H}_{2} \mathrm{O}_{2}(280 \mu \mathrm{M})$ and TMB $(1.4 \mathrm{mM})$ for $3 \mathrm{~min}$. The reaction was quenched with catalase (100 units/mL) and $200 \mathrm{mM}$ ice-cold acetic acid in water and then the absorbance at $655 \mathrm{~nm}$ was read. Inset: Effect of typical peroxidase inhibitors (methimazole, ABAH, and azide, $1 \mathrm{mM}$ each) on TMB oxidation. (B) Peroxidase activity in FBS from different commercial sources (different lots) determined using the TMB assay. Serum \#1, Gibco-BRL; Serum \#2, Hyclone; Serum \#3, Hyclone (heat inactivated $56{ }^{\circ} \mathrm{C}$ for $1 \mathrm{~h}$ ); Serum \#4, Hyclone; Serum \#5, Gibco-BRL; Serum \#6, Hyclone.

we fractionated sera using a Centricon 10000 molecular weight (MW) centrifugal filter and then assayed the fractionated sera for peroxidase activity and the ability to oxidize DOX. Using the TMB assay, it was found that the $>10000$ MW fraction had peroxidase activity higher by $34 \%$ compared to the unfractionated sera (not shown). Less than $5 \%$ of the activity was found in the $<10000 \mathrm{MW}$ fraction. These results suggest that free heme and low molecular weight heme peptides are not the major source of the peroxidative activity in FBS and points to compound(s) of MW greater than 10000, possibly heme proteins, as a carrier of this activity. When the same fractions were placed in PBS ( $\mathrm{pH} 7.0$ ) and incubated with DOX in the presence of $\mathrm{H}_{2} \mathrm{O}_{2}$ and $\mathrm{NaNO}_{2}$ ( $1 \mathrm{mM}$ each), the unfractionated sera and the $>10000$ MW fraction caused oxidation of approximately $75 \%$ of the drug (Figure 5). The $<10000$ MW fraction caused virtually no change in the concentration of DOX under the same conditions (Figure 5). We also found that FBS that was exhaustively dialyzed appeared to be more effective in supporting oxidation of DOX by $\mathrm{H}_{2} \mathrm{O}_{2}$ than nondialyzed FBS, both in the absence and presence of nitrite (not shown). This is most likely due to removal of low molecular weight reducing agents from FBS preparations, such as ascorbate, that could inhibit DOX oxidation.

Determination of Serum Heme Content. The peroxidative activity is most likely due to the presence of heme proteins in the sera. We determined that the amount of heme in various FBS preparations varied between 1.1 and $2.0 \mu \mathrm{M}$, median $=$ $1.8 \mu \mathrm{M}(n=5)$. Differences in the heme content among the FBSs studied were $<20.3 \%$ and differences in the peroxidative activity were $<23.3 \%$. Thus, there is good correlation between the heme content and the peroxidative activity. 


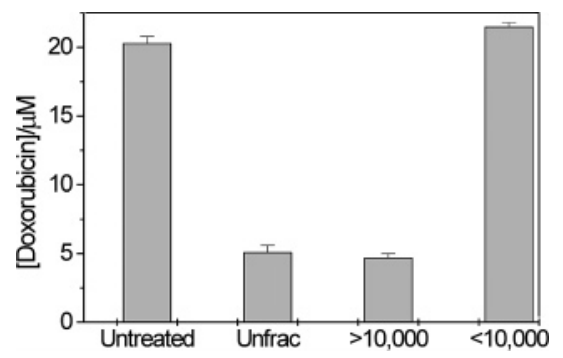

Figure 5. Peroxidase activity of fetal bovine serum is contained in the $>10000$ MW fraction. Serum was fractionated using Centricon Centrifugal Filter Units and the ability of the resultant fractions to oxidize DOX was then studied. Unfrac (unfractionated) is DOX incubated with $1 \mathrm{mM}$ nitrite and $\mathrm{H}_{2} \mathrm{O}_{2}$ in FBS for $60 \mathrm{~min}$. Untreated (control) is DOX alone incubated with FBS for $60 \mathrm{~min}$.

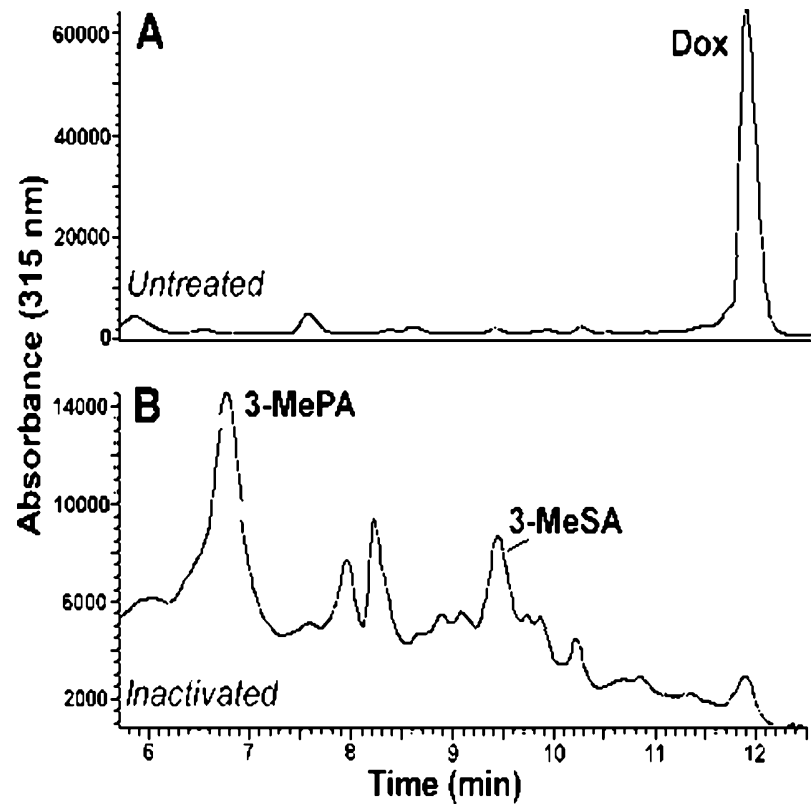

Figure 6. HPLC chromatograms. Samples analyzed by LC/MS showing DOX (panel A) and its oxidation products, 3MePA and 3MeSA (panel B). DOX $(100 \mu \mathrm{M})$ was added to FBS and was treated with 1 $\mathrm{mM}$ nitrite and $1 \mathrm{mM} \mathrm{H} \mathrm{O}_{2}$ for $1 \mathrm{~h}$. Then catalase $(100 \mathrm{U} / \mathrm{mL})$ was added to remove residual $\mathrm{H}_{2} \mathrm{O}_{2}$, and the samples were fractionated with a $3000 \mathrm{MW}$ cutoff centrifugal device. The filtrates were then analyzed by HPLC using authentic 3-MePA and 3-MeSA as standards. Shown are representative HPLC scans.

Quantitation of Loss of Doxorubicin and Accumulation of Metabolites. We estimated the amount of DOX lost and the quantity of major metabolic products generated by oxidation of DOX with $\mathrm{FBS} / \mathrm{H}_{2} \mathrm{O}_{2}$. In separate replicate experiments the drug was exposed to FBS in the presence of $\mathrm{H}_{2} \mathrm{O}_{2}$ and $\mathrm{NaNO}_{2}$. Oxidation of DOX $(93.3 \pm 3.4 \mu \mathrm{M})$ generated 3MePA $(26.8 \pm$ $4.4 \mu \mathrm{M})$ and $3 \mathrm{MeSA}(2.3 \pm 1.2 \mu \mathrm{M})$. This indicates that $29 \%$ of the parent drug was converted to 3MePA and $3.0 \%$ to 3MeSA. By spectrophotometry, only $6.7 \mu \mathrm{M}$ or $7.2 \%$ DOX remained after $1 \mathrm{~h}$ incubation. The yields were determined by HPLC based on standard curves of purified reference compounds. Figure 6 shows a typical HPLC chromatogram of the intact and oxidized DOX. The identity of the products derived from oxidized DOX was further confirmed using mass spectroscopy. Figure 7 shows MS/MS spectra of negative ions (M$\mathrm{H})^{-}$of 3MeSA, $\mathrm{m} / \mathrm{z} 167.1$ (A), and 3MePA, $\mathrm{m} / \mathrm{z} 195.1$ (B), detected in samples containing oxidized DOX. In (A) the ions of $\mathrm{m} / \mathrm{z}, 152.1$ and 123.1 are assigned to 3MeSA after loss of methyl and $\mathrm{CO}_{2}$ groups, respectively. The ion of $\mathrm{m} / \mathrm{z} 108.1$ is the ion of 152.1 after loss of $\mathrm{CO}_{2}$ group. In (B), the ion of $\mathrm{m} / z$ 151.1 is from $3 \mathrm{MePA}$ after loss of $\mathrm{CO}_{2}$ group. These data are
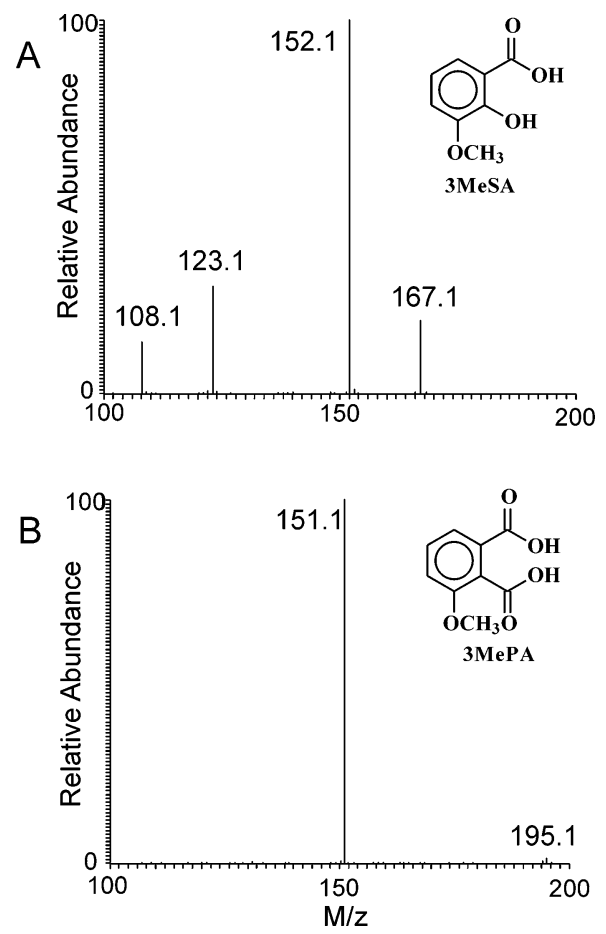

Figure 7. MS/MS spectra of doxorubicin oxidized by serum $/ \mathrm{H}_{2} \mathrm{O}_{2}$. CID tandem mass spectra of negative ions $(\mathrm{M}-\mathrm{H})^{-}$of $\mathrm{m} / \mathrm{z} 167.1$ (A) and 195.1 (B) attributed to 3MeSA and 3MePA, respectively. In (A) the ions of $\mathrm{m} / z 152.1$ and 123.1 are from 3MeSA after loss of methyl and $\mathrm{CO}_{2}$ groups, respectively. The ion of $\mathrm{m} / \mathrm{z} 108.1$ is the ion of 152.1 after loss of $\mathrm{CO}_{2}$ group. In (B), the ion of $\mathrm{m} / z, 151.1$ is from 3MePA after loss of $\mathrm{CO}_{2}$ group. The assignment was based on comparison with mass spectra of authentic 3MeSA and 3MePA samples.

in agreement with earlier reports in which DOX was exposed to different oxidizing systems $(2,5,20)$.

Oxidation of Doxorubicin by metHemoglobin/ $/ \mathrm{H}_{2} \mathrm{O}_{2}$. Because hemoglobin from ruptured erythrocytes is likely to be present in serum, and because hemoglobin possesses pseudoperoxidase activity, we examined the capacity of hemoglobin to support oxidation of DOX by $\mathrm{H}_{2} \mathrm{O}_{2}$. We used the commercial equine $\mathrm{Hb}$ that is present mostly in metHb (ferric) form. When DOX was incubated with metHb in the presence of $\mathrm{H}_{2} \mathrm{O}_{2}$, oxidation of the drug was apparent (Figure 8A, main panel). The inset in Figure 8A shows the corresponding time course of absorption changes at $480 \mathrm{~nm}$ (trace a) as a measure of DOX oxidation. Nitrite $(0.33 \mathrm{mM})$ markedly accelerated DOX oxidation (Figure $8 \mathrm{~A}$, inset trace $\mathrm{b}$ ). No oxidation of DOX was observed when the drug was incubated with metHb alone (initial sector of the runs) or when metHb was omitted but $\mathrm{H}_{2} \mathrm{O}_{2}$ was present (Figure 8A, inset trace c). This demonstrates that metHb is capable of oxidizing DOX in the presence of the peroxide alone. Figure $8 \mathrm{~A}$ also shows spectral changes in the $\mathrm{Hb}$ Soret band $(405 \mathrm{~nm})$ during DOX oxidation in the presence of nitrite. These observations are also confirmed using human hemoglobin $\mathrm{A}_{0}$ (data not shown).

Exposure of metHb to $\mathrm{H}_{2} \mathrm{O}_{2}$ generates an analog of peroxidase compound I containing oxo-ferrylHb $\left(\mathrm{Fe}^{\mathrm{IV}}=\mathrm{O}\right)$ and a $\pi$ cation radical located on the porphyrin ring of the heme group. In the absence of an appropriate oxidizable substrate the radical site migrates from the porphyrin ring to the protein $(13,21)$. Reduction of this radical yields a product, which resembles peroxidase compound II. Both of these forms contain the oxoferryl moiety known to oxidize biological substrates (21). To determine whether oxo-ferrylHb is responsible for oxidation of DOX, it was prepared first by adding an excess of $\mathrm{H}_{2} \mathrm{O}_{2}(0.37$ $\mathrm{mM})$ to metHb $(\sim 50 \mu \mathrm{M})$ in $\mathrm{pH} 7.0$ buffer. This caused a 

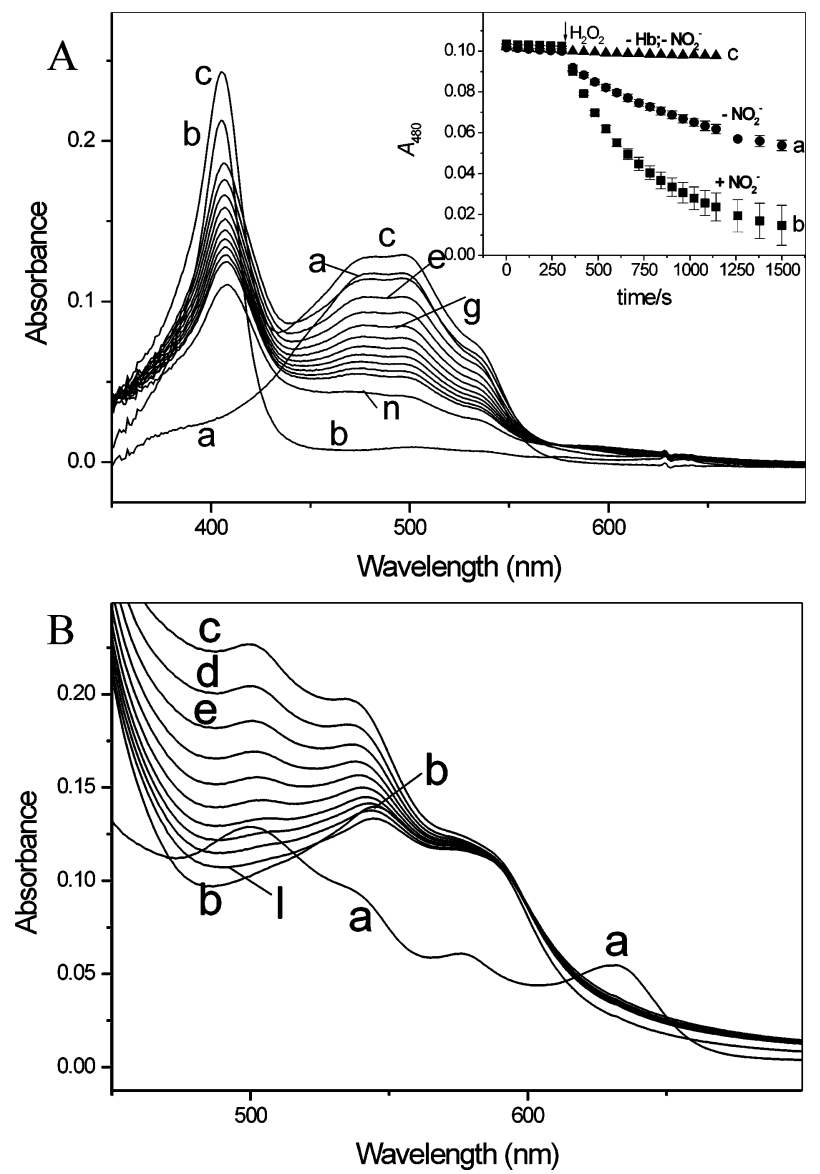

Figure 8. $\mathrm{DOX}$ is oxidized by metHb/ $\mathrm{H}_{2} \mathrm{O}_{2}$ in $\mathrm{pH} 7.0$ buffer. (A) Absorption spectra in the main panel are from DOX $(10 \mu \mathrm{M})$ reacting with metHb $(1.3 \mu \mathrm{M})$ and $\mathrm{H}_{2} \mathrm{O}_{2}(0.33 \mathrm{mM})$ and $\mathrm{NaNO}_{2}(0.3 \mathrm{mM})$. Spectra (a) DOX alone, (b) Hb alone, (c) DOX and Hb. Spectra (d)(n) were recorded in 1 min intervals following $\mathrm{H}_{2} \mathrm{O}_{2}$ addition. Inset: Time course of DOX oxidation, measured as absorption changes at $480 \mathrm{~nm}$, recorded with $\mathrm{NaNO}_{2}$ omitted, $\mathrm{NaNO}_{2}$ present $(0.3 \mathrm{mM})$, and $\mathrm{Hb}$ omitted for traces (a), (b), and (c), respectively. (B) Reaction of DOX with preformed ferrylHb. Spectrum (a) metHb $(\sim 50 \mu \mathrm{M})$ alone; (b) spectrum of ferryl $\mathrm{Hb}$ recorded 3 min after addition of $\mathrm{H}_{2} \mathrm{O}_{2}$ $(0.37 \mathrm{mM})$. To this ferrylHb was added DOX $(10 \mu \mathrm{M})$ and spectra were recorded every $1 \mathrm{~min}(\mathrm{c})-(\mathrm{k})$. Spectrum 1 was recorded $3 \mathrm{~min}$ after (k).

decrease in absorbance at 500 and $630 \mathrm{~nm}$, characteristic of metHb, and was concomitant with the formation of a new band at $545 \mathrm{~nm}$, which is interpreted as a redox transition from metHb to ferrylHb (13). To this preformed oxo-ferrylHb, an aliquot of DOX solution was added. Changes in absorption spectra indicate that DOX was undergoing oxidation (Figure 8B, traces $\mathrm{c}-1$ ). There was a momentary recovery of metHb (transient appearance of the absorption peak at $500 \mathrm{~nm}$ ), and as the DOX level was decreasing to a minimum, the gradual loss of metHb (disappearance of the absorption peak at $500 \mathrm{~nm}$ ) was followed by re-formation of oxo-ferryl $\mathrm{Hb}$, presumably due to reaction with unreacted $\mathrm{H}_{2} \mathrm{O}_{2}$. These observations support the suggestion that ferrylHb may be involved in DOX oxidation.

Effect of DOX Oxidation on Cytotoxicity. We have previously shown that DOX oxidized by $\mathrm{LPO} / \mathrm{H}_{2} \mathrm{O}_{2} / \mathrm{NO}_{2}{ }^{-}$or by MPO-positive HL- 60 cells $/ \mathrm{H}_{2} \mathrm{O}_{2} / \mathrm{NO}_{2}{ }^{-}$systems is markedly less cytotoxic for human PC3 prostate cancer cells and for rat cardiac myocytes $\mathrm{H} 9 \mathrm{c} 2$ cells in vitro (2). We were interested to find out whether oxidation of DOX by FBS also decreases its cytotoxicity. DOX was treated with the whole FBS containing $\mathrm{NO}_{2}{ }^{-}(1 \mathrm{mM})$ in the presence of $\mathrm{H}_{2} \mathrm{O}_{2}(1 \mathrm{mM})$ for $1 \mathrm{~h}$, after which the levels of DOX decreased by $\sim 90 \%$. The control

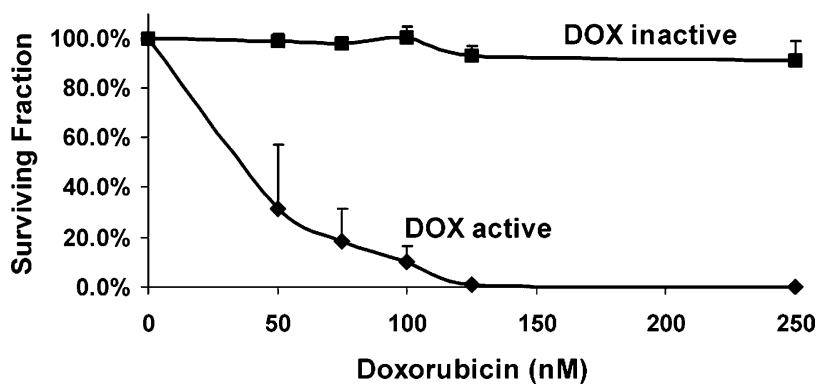

Figure 9. Cytotoxicity of DOX for PC3 prostate cancer cells is lost upon oxidation. DOX $(93 \mu \mathrm{M})$ was treated for $1 \mathrm{~h}$ with nitrite $(1 \mathrm{mM})$ in full serum in the presence or absence of $\mathrm{H}_{2} \mathrm{O}_{2}(1 \mathrm{mM})$. Next, catalase (500 units $/ \mathrm{mL}$ ) was added to all samples, which were then filtered and the amount of DOX remaining was determined spectrophotometrically at $480 \mathrm{~nm}$. During this time the concentration of DOX decreased to 6.7 and $83 \mu \mathrm{M}$, for the complete system and the system with $\mathrm{H}_{2} \mathrm{O}_{2}$ omitted, respectively. Aliquots of the FBS containing active (sham treated) and oxidized DOX were added to PC3 cells at equivalent volumes. The cells were exposed to DOX and its degradation products for 10 days after which their clonogenic survival was determined. Results shown are mean \pm SE from three separate studies. DOX inactive and DOX active data are for cell survival determined for cells exposed to oxidized and intact DOX, respectively.

sample was treated in the same fashion but with $\mathrm{H}_{2} \mathrm{O}_{2}$ omitted. Aliquots of the FBS containing active (sham treated) and oxidized DOX were added to PC3 cells at equivalent volumes and incubated for 10 days after which their clonogenic survival was determined. Figure 9 shows that clonogenic survival is much higher in cells treated with oxidized DOX than with the intact drug. Thus, oxidation of DOX catalyzed by serum causes inactivation of the drug.

\section{Discussion}

Our results demonstrate that FBS contains a peroxidase-like activity that can support oxidation of DOX by exogenous $\mathrm{H}_{2} \mathrm{O}_{2}$. The oxidation of the drug is substantial, causing about $90 \%$ loss of the initial drug level. The process is stimulated by nitrite, which is consistent with our earlier observations using true peroxidases $(1,2)$. Most importantly, products of this oxidative modification of DOX are nontoxic for PC3 prostate cancer cells in vitro when compared to the parent drug, confirming that oxidation of DOX leads to its inactivation. We believe that these observations may have implications for the therapeutic efficacy of anthracyclines, as they suggest that components of sera may diminish the drug's tumoricidal activity.

We have shown that a component of FBS with a molecular mass $>10000 \mathrm{Da}$, possibly a heme protein, exerts this peroxidase-like activity. According to manufacturers' specifications, commercial FBS contains up to $25 \mathrm{mg} \%$ hemoglobin, which corresponds to $\sim 3.8 \mu \mathrm{M}$ (based on MW 64500), which is close to heme contents determined in FBSs in this study. Given the above, and considering that $\mathrm{Hb} / \mathrm{H}_{2} \mathrm{O}_{2}$ is capable of oxidizing DOX, as observed in this study, it seems likely that this activity is due, at least partially, to $\mathrm{Hb}$ present naturally in FBS. Importantly, the $\mathrm{Hb} / \mathrm{H}_{2} \mathrm{O}_{2}$ system, similar to other peroxidative systems, oxidizes $\mathrm{NO}_{2}^{-}$, causing self-nitration as well as nitration of other proteins (22). These processes are mediated by reactive nitrogen species derived from nitrite, and the same species may play a role in oxidation of DOX (1). Thus, our observation that $\mathrm{NO}_{2}{ }^{-}$enhances oxidation of $\mathrm{DOX}$ by metHb/ $\mathrm{H}_{2} \mathrm{O}_{2}$ is consistent with these earlier reports. We also wish to emphasize that myoglobin, a protein functionally related to $\mathrm{Hb}$, has been shown to oxidize anthracyclines in the presence of $\mathrm{H}_{2} \mathrm{O}_{2}(5,19)$. 
We also considered two other heme proteins as possible candidates for the serum peroxidase, namely, MPO and LPO, both of which have been shown to support oxidation of anthracyclines by $\mathrm{H}_{2} \mathrm{O}_{2}$ in the presence of nitrite $(1,2)$. Human serum contains MPO in the range from 5.4 to $\sim 140 \mu \mathrm{g} / \mathrm{L}$ depending on age, sex, and apparent genetic factors (9). MPO levels ranging from 1.5 to $\sim 1100 \mu \mathrm{g} / \mathrm{L}$ have been measured in human serum from patients with acute coronary syndromes and, as the authors elaborated, these levels were measured in patients that had received heparin (10). Therefore, MPO levels may have been elevated due to release from endothelium into the circulation. Additionally, it has been found in in vivo studies that MPO can be localized during inflammation in vascular endothelial cells and sub-endothelial spaces where it may modulate NO availability (23-25). These studies clearly demonstrate that MPO is present in human serum at measurable levels. In contrast to MPO, the presence of LPO in FBS is less likely.

FBS is used routinely in many cell culture studies examining cytotoxicity of anticancer drugs. Results of our studies show that attention has to be paid to the possibility that FBS components may influence the outcome of such studies. It is also highly likely that cofactors other than $\mathrm{NO}_{2}^{-}$may act catalytically in such processes as demonstrated for acetaminophen or salicylic acid in LPO and MPO systems $(3,4)$. An earlier study on the interaction of DOX with rat serum indicated that DOX undergoes one-electron reduction to a radical that could be detected by EPR, but only in anaerobic media (26). The reaction required $\mathrm{NAD}(\mathrm{P}) \mathrm{H}$ as electron donors; inhibitors of flavoenzymes inhibited radical formation. In addition, the EPR signal of the DOX radical was absent in the presence of air. Clearly, this metabolism is different from that observed in the present study. Specifically, the reductive metabolism of DOX and its redox cycling do not cause modification of the drug's chromophore; thus, its redox properties are maintained. In contrast, oxidation of DOX leads to its degradation, which clearly is an irreversible process.

How relevant are these observations to the therapeutic action of DOX? Since during chemotherapy DOX is administered intravenously, it may interact directly with various blood components including $\mathrm{Hb}$ and MPO. It has been reported that a significant portion of administered drug is bound to circulating erythrocytes (27). The question is whether this interaction can cause inactivation of DOX. Results of our study suggest that oxo-ferryl $\mathrm{Hb}$, which can be generated from either metHb or oxyHb $\left(\mathrm{HbO}_{2}\right)$ by the action of $\mathrm{H}_{2} \mathrm{O}_{2}(13)$, oxidizes DOX. $\mathrm{H}_{2} \mathrm{O}_{2}$ is generated in vivo during normal physiological processes, but its level is markedly increased under oxidative stress conditions. $\mathrm{OxyHb}$ undergoes autoxidation forming metHb and superoxide, which ultimately produces $\mathrm{H}_{2} \mathrm{O}_{2}(28)$. Nitrite oxidizes $\mathrm{HbO}_{2}$ to metHb in a reaction that also produces $\mathrm{H}_{2} \mathrm{O}_{2}$ (29). In addition, in cellular systems the peroxide is generated by anthracyclines themselves via aerobic redox cycling (8). Erythrocytes are the major reservoir of nitrite in human blood (30). The natural level of nitrite in erythrocytes has been determined to be $288 \pm 47$ $\mathrm{nM}$, much higher than that in plasma or whole blood (30). The levels of nitrite are even higher in disease states due to increased activity of nitric oxide synthase. Therefore, a complete enzymatic system necessary for inactivating DOX may exist in the blood. It has to be emphasized, however, that in vivo $\mathrm{H}_{2} \mathrm{O}_{2}$ is rapidly removed by catalase and/or glutathione peroxidase, which limits the availability of the peroxide for other reactions. Oxidation of DOX may also be inhibited by endogenous antioxidants such as ascorbate or glutathione. Thus, oxidative inactivation of DOX in vivo may occur under specific conditions characterized by the absence, or sufficiently low levels, of antioxidant systems. The report that $3 \mathrm{MePA}$ accumulates in tissues, especially in the heart, of mice administered DOX strongly supports occurrence of oxidative degradation of DOX in vivo (5). In this case degradation of DOX was linked to its oxidation by myoglobin, a protein especially abundant in the heart $(5,19)$. It needs to be emphasized that levels of antioxidant enzymes are particularly low in the heart $(31,32)$.

Our observations may be pertinent to clinical pharmacology and toxicology of anthracyclines. Animal and human studies have shown a large disparity in the drugs' recovery from various tissues determined by fluorescence and radioactivity measurements $(33,34)$. The lower recovery of the fluorescent materials was interpreted as indicating either binding of drugs to cellular components in a fashion that does not allow for their extraction or, more likely, that they undergo a metabolic transformation to nonfluorescing products. DOX, its major metabolite doxorubicinol, and DOX-derived aglycones show similar fluorescence excitation and emission spectra; they all possess the same intact original chromophore. However, products of the oxidative transformation of DOX, 3MePA and 3MeSA, do not absorb at $480 \mathrm{~nm}$ and therefore do not fluoresce when excited at this wavelength. Our observations lend strong support to the idea that the low recovery of the fluorescent metabolites may indeed be the consequence of an extensive degradation of DOX and suggests that this process may be oxidative in nature. Finally, it should be mentioned that results described in this report on DOX are fully applicable to a related anthracycline, daunorubicin (not shown). Further studies are needed to elucidate the role of the oxidative pathway in the metabolic inactivation of anthracyclines and assess biological properties of their degradation products in vivo.

\section{Summary}

We have shown that serum in the presence of $\mathrm{H}_{2} \mathrm{O}_{2}$ oxidizes DOX to nontoxic products and that nitrite markedly stimulates this reaction. The major role in this metabolism of DOX has been attributed to hemoglobin, which is present naturally in sera. Occurrence of such a reaction in vivo would substantially diminish the therapeutic efficacy of the drug. This study emphasizes that addition of $\mathrm{H}_{2} \mathrm{O}_{2}$ to media containing FBS will stimulate peroxidase-type of reactions, which may affect cytotoxic properties of studied compounds. Inactivation of anthracyclines described in this study is only one example of possible complications resulting from such reactions.

Acknowledgment. This investigation was supported by Grants P01 CA66081 (C.P.B., G.R.B.) awarded by the National Cancer Institute, R01 AI 34954 (B.E.B.) awarded by the National Institute of Allergy and Infectious Diseases, Department of Health and Human Services, and Merit Awards from the VA Research Service to B.E.B., The Dr. Richard O. Emmons Memorial Fund, The Mamie C. Hopkins Fund, and The Iowa Leukemia and Cancer Research Fund.

\section{References}

(1) Reszka, K. J., McCormick, M. L., and Britigan, B. E. (2001) Peroxidase- and nitrite-dependent metabolism of the anthracycline anticancer agents daunorubicin and doxorubicin. Biochemistry 40 (50), 15349-15361.

(2) Reszka, K. J., Wagner, B. A., Teesch, L. M., Britigan, B. E., Spitz, D. R., and Burns, C. P. (2005) Inactivation of anthracyclines by cellular peroxidase. Cancer Res. 65 (14), 6346-6353. 
(3) Reszka, K. J., Britigan, L. H., Rasmussen, G. T., Wagner, B. A., Burns, C. P., and Britigan, B. E. (2004) Acetaminophen stimulates the peroxidative metabolism of anthracyclines. Arch. Biochem. Biophys. 427 (1), 16-29.

(4) Reszka, K. J., Britigan, L. H., and Britigan, B. E. (2005) Oxidation of anthracyclines by peroxidase metabolites of salicylic acid. $J$. Pharmacol. Exp. Ther. 315 (1), 283-290.

(5) Cartoni, A., Menna, P., Salvatorelli, E., Braghiroli, D., Giampietro, R., Animati, F., Urbani, A., Del Boccio, P., and Minotti, G. (2004) Oxidative degradation of cardiotoxic anticancer anthracyclines to phthalic acids. Novel function or ferrylmyoglobin. J. Biol. Chem. 279 (7), 5088-5099

(6) Szatrowski, T. P., and Nathan, C. F. (1991) Production of large amounts of hydrogen peroxide by human tumor cells. Cancer Res. 51 (3), 794-798.

(7) Buettner, G. R., Ng, C. F., Wang, M., Rodgers, V. G. J., and Schafer, F. Q. (2006) A new paradigm: Manganese superoxide dismutase influences the production of $\mathrm{H}_{2} \mathrm{O}_{2}$ in cells and thereby their biological state. Free Radic. Biol. Med. 41 (8), 1338-1350.

(8) Wagner, B. A., Evig, C. B., Reszka, K. J., Buettner, G. R., and Burns, C. P. (2005) Doxorubicin increases intracellular hydrogen peroxide in PC3 prostate cancer cells. Arch. Biochem. Biophys. 440 (2), 181190.

(9) Hoy, A., Tregouet, D., Leininger-Muller, B., Poirier, O., Maurice, M., Sass, C., Siest, G., Tiret, L., and Visvikis, S. (2001) Serum myeloperoxidase concentration in a healthy population: biological variations, familial resemblance and new genetic polymorphisms. Eur. J. Hum. Genet. 9 (10), 780-786.

(10) Baldus, S., Heeschen, C., Meinertz, T., Zeiher, A. M., Eiserich, J. P., Munzel, T., Simoons, M. L., and Hamm, C. W. (2003) Myeloperoxidase serum levels predict risk in patients with acute coronary syndromes. Circulation 108 (12), 1440-1445.

(11) Lau, D., Mollnau, H., Eiserich, J. P., Freeman, B. A., Daiber, A. Gehling, U. M., Brummer, J., Rudolph, V., Munzel, T., Heitzer, T., Meinertz, T., and Baldus, S. (2005) Myeloperoxidase mediates neutrophil activation by association with CD11b/CD18 integrins. Proc. Natl. Acad. Sci. U.S.A. 102 (2), 431-436.

(12) Chaires, J. B., Dattagupta, N., and Crothers, D. M. (1982) Selfassociation of daunomycin. Biochemistry 21 (17), 3927-3932.

(13) Giulivi, C., and Davies, K. J. A. (1994) Hydrogen peroxide-mediated ferrylhemoglobin generation in vitro and in red blood cells. Methods Enzymol. 231, 490-496.

(14) Antonini, E., and Brunori, M. (1971) Hemoglobin and myoglobin in their reactions with ligands. North-Holland Publ. Co., New York.

(15) Bozeman, P. M., Learn, D. B., and Thomas, E. L. (1990) Assay of the human leukocyte enzymes myeloperoxidase and eosinophil peroxidase. J. Immunol. Methods 126 (1), 125-133.

(16) Lombardo, M. E., Araujo, L. S., Ciccarelli, A. B., and Batlle, A. (2005) A spectrophotometric method for estimating hemin in biological systems. Anal. Biochem. 341 (2), 199-203.

(17) Evig, C. B., Kelley, E. E., Weydert, C. J., Chu, Y., Buettner, G. R., and Burns, C. P. (2004) Endogenous production and exogenous exposure to nitric oxide augment doxorubicin cytotoxicity for breast cancer cells but not cardiac myoblasts. Nitric Oxide 10 (3), 119129.

(18) Reszka, K. J., McCormick, M. L., and Britigan, B. E. (2003) Oxidation of anthracycline anticancer agents by the peroxidase mimic microperoxidase 11 and hydrogen peroxide. Free Radic. Biol. Med. 35 (1) $78-93$.
(19) Menna, P., Salvatorelli, E., Giampietro, R., Liberi, G., Teodori, G., Calafiore, A. M., and Minotti, G. (2002) Doxorubicin-dependent reduction of ferrylmyoglobin and inhibition of lipid peroxidation: implications for cardiotoxicity of anticancer anthracyclines. Chem. Res Toxicol. 15 (9), 1179-1189.

(20) Ramu, A., Mehta, M. M., Liu, J., Turyan, I., and Aleksic, A. (2000) The riboflavin-mediated photooxidation of doxorubicin. Cancer Chemother. Pharmacol. 46, 449-458.

(21) Everse, J., and Hsia, N. (1997) The toxicities of native and modified hemoglobins. Free Radic. Biol. Med. 22 (6), 1075-1099.

(22) Grzelak, A., Balcerczyk, A., Mateja, A., and Bartosz, G. (2001) Hemoglobin can nitrate itself and other proteins. Biochim. Biophys. Acta 1528 (2-3), 97-100.

(23) Zhang, R., Brennan, M. L., Fu, X., Aviles, R. J., Pearce, G. L., Penn, M. S., Topol, E. J., Sprecher, D. L., and Hazen, S. L. (2001) Association between myeloperoxidase levels and risk of coronary artery disease. J. Am. Med. Assoc. 286 (17), 2136-2142.

(24) Eiserich, J. P., Baldus, S., Brennan, M. L., Ma, W., Zhang, C., Tousson, A., Castro, L., Lusis, A. J., Nauseef, W. M., White, C. R., and Freeman, B. A. (2002) Myeloperoxidase, a leukocyte-derived vascular NO oxidase. Science 296 (5577), 2391-2394.

(25) Vita, J. A., Brennan, M. L., Gokce, N., Mann, S. A., Goormastic, M., Shishehbor, M. H., Penn, M. S., Keaney, J. F., Jr., and Hazen, S. L. (2004) Serum myeloperoxidase levels independently predict endothelial dysfunction in humans. Circulation 110 (9), 1134-1139.

(26) Miura, T., Muraoka, S., and Ogiso, T. (1991) Generation of adriamycin radical by interaction of adriamycin with serum. Res. Commun. Chem. Pathol. Pharmacol. 71 (1), 115-124.

(27) Broggini, M., Colombo, T., Garattini, S., and Donelli, M. G. (1980) Influence of tumor on adriamycin concentration in blood cells. Cancer Chemother. Pharmacol. 4, 209-212.

(28) Wallace, W. J., Maxwell, J. C., and Caughey, W. S. (1974) The mechanisms of hemoglobin autoxidation evidence for proton-assisted nucleophilic displacement of superoxide by anions. Biochem. Biophys. Res. Commun. 57 (4), 1104-1110.

(29) Doyle, M. P., Pickering, R. A., Dykstra, R. L., Nelson, C. L., and Boyer, R. F. (1982) Involvement of peroxide and superoxide in the oxidation of hemoglobin by nitrite. Biochem. Biophys. Res. Commun. 105 (1), 127-132.

(30) Dejam, A., Hunter, C. J., Pelletier, M. M., Hsu, L. L., Machado, R. F., Shiva, S., Power, G. G., Kelm, M., Gladwin, M. T., and Schechter, A. N. (2005) Erythrocytes are the major intravascular storage sites of nitrite in human blood. Blood 106 (2), 734-739.

(31) Doroshow, J. H., Locker, G. Y., and Myers, C. E. (1980) Enzymatic defenses of the mouse heart against reactive oxygen metabolites: alterations produced by doxorubicin. J. Clin. Invest. 65, 128-135.

(32) Oberley, L. W. (1982) Superoxide dismutase and cancer. In Superoxide Dismutase (Oberley, L. W., Ed.) Vol. II, pp 127-165, CRC Press, Boca Raton, FL.

(33) Alberts, D. A., Bachur, N. R., and Holtzman, J. L. (1971) The pharmacokinetics of daunomycin in man. Clin. Pharm. Ther. 12, 96104.

(34) Takanashi, S., and Bachur, N. R. (1976) Adriamycin metabolism in man. Drug Metab. Dispos. 4, 79-87.

TX700002F 